\title{
Bus Transit Service Planning and Operations in a Competitive Environment
}

\author{
Ahmed M. El-Geneidy, McGill University \\ John Hourdos, University of Minnesota \\ Jessica Horning, Cambridge Systematics, Inc.
}

\begin{abstract}
Transit services are currently facing several challenges in the United States and around the world. For many reasons, among which the fluctuations in gas prices and the state of the economy are the major ones, transit demand has noticed a considerable increase. The challenge that transit agencies are facing is to make these increases permanent by maintaining transit's competitive edge over the private vehicle with more dense and reliable service. Current methodologies for scheduling new as well as improving existing transit routes should be able to respond to the dynamic nature of urban traffic as it is evolving through ITS and more comprehensive traffic management strategies. In this research paper, we correlate travel time obtained from buses to travel time obtained from floating vehicles in the Twin Cities metropolitan region. This research helps to introduce more reliable estimates of travel time for planning new and competitive transit services. Specifically, this work studied two bus routes over a variety of different roadway types and traffic conditions and produced statistical models that can estimate travel time based on measurements collected from buses and regular vehicle probes. The generated models revealed the characteristics causing bus service to be generally slower. Altering bus route characteristics can reduce overall travel time and minimize the travel time disparity between buses and private vehicles. In particular, the models presented in this paper lend support to
\end{abstract}


bus-only shoulder policies, stop consolidation, serving major streets with fewer stop signs, and implementation of smart transit signal priority.

\section{Introduction}

Transit services are facing several challenges around the world, even more in the United States. In recent days transit demand has noticed an increase, which some researcher relate to the increase in gas prices. For such surge in demand to become permanent, transit agencies need to manage their systems strategically and offer a service that can be competitive to private vehicles. A service competitive to private vehicles is possible when a reliable service to passengers is present. A reliable service to a passenger is the service that can be easily accessed at origin and destination, arrives on time, has a short travel time/run time (similar or better than private vehicle travel time), and has low variance in travel time and a short waiting time (Furth and Muller 2006, 2007; Koenig 1980; Murray and Wu 2003; Turnquist 1978; Welding 1957). Achieving such service requires expanding the existing transit operations with routes that follow realistic schedules to which a bus can adhere, in addition to improving the existing service in several aspects. Schedulers rely primarily on using software that is designed based on operations research methods to introduce schedules for new bus services. Such software takes into account the expected operating environment. Unfortunately, a generic solution in transit planning based on optimization is not the best way to go and always requires some kind of fine-tuning. Some transit agencies use floating vehicles driving along corridors where new routes are planned. The vehicles are used to estimate travel time and compare it to schedules generated from optimization software prior to implementation of new service. Doing so without having an accurate understanding of the differences between floating cars and real bus service makes the outputs questionable. Currently, several agencies are looking toward increased implementation of faster services such as limited, express, and Bus Rapid Transit (BRT) services. By implementing these services, transit agencies try to compete with private vehicles to attract more choice riders (Krizek and El-Geneidy 2007). Implementing any of these services requires a full understanding of the operating environment. In this research paper, we correlate travel time obtained from buses to travel time obtained from floating vehicles in the Twin Cities metropolitan region. This research helps to introduce more reliable estimates of travel time for planning new and competitive transit services. Previous research concentrating on relating travel time between buses and floating vehicles along 
corridors used visualization and simple statistics (Bertini and Tantiyanugulchai 2004). They concentrated mainly on the use of transit vehicles as probes to estimate corridor travel time for systemwide implementation. Although this is not the focus of this study, findings from this study can be used in a similar manner as well. The main goal of this research is to better understand the factors affecting bus travel time towards offering a competitive service to the private vehicle in a highly complex environment. In this research, we analyze information from different roadway types (freeways, arterials, and local streets) to uncover potential traffic-flow-related dependencies.

\section{Literature Review}

\section{Travel/Run Time}

Travel time, or run time, is the amount of time it takes for a bus to travel along its route or along a specified segment. Abkowitz and Engelstein (1984) found that mean run time is affected by route length, passenger activity, and number of signalized intersections. Most researchers agree on the basic factors affecting bus run times (Abkowitz and Engelstein 1983; Abkowitz and Tozzi 1987; Guenthner and Sinha 1983; Levinson 1983; Strathman, et al. 2000). Table 1 contains a summary of known factors affecting run times.

\section{Table 1. Factors Affecting Transit Travel Times}

\begin{tabular}{ll}
\hline Variables & Description \\
\hline Distance & Segment length \\
Intersections & Number of signalized intersections \\
Bus stops & Number of bus stops \\
Boarding & Number of passenger boardings \\
Alighting & Number of passenger alightings \\
Time & Time period \\
Driver & Driver experience \\
Period of service & How long the driver has been on service in the study period \\
Departure delay & Observed departure time minus scheduled \\
Stop delay time & Time lost in stops based on bus configuration (low floor, etc.) \\
Nonrecurring events & Lift usage, bridge opening, etc. \\
Direction & Inbound or outbound service \\
Weather & Weather-related conditions \\
Road & Road characteristics \\
\hline
\end{tabular}


Since buses travel with regular traffic, they are affected by the overall dynamics of the transportation system, where changes occur on both regular (i.e., peak hour traffic congestion) and random (i.e., road construction, accidents, special events) bases. These changes influence the amount of time it takes for a bus to travel from one stop to another and the level of service it provides to passengers. Street characteristic is another major element affecting bus travel time. For example, in the Twin Cities region, buses are allowed to use highway shoulders when the speed along the main lanes drops below 35 miles/hour. Buses can drive as fast as 15 miles/hour faster than the regular traffic sitting in the congested lanes, but they cannot exceed the 35 miles/hour threshold. These special privileges that buses have along the Twin Cities highway system makes estimating their travel time through regular practices difficult. It also gives buses an advantage over regular vehicles in terms of speed. Accordingly, relating travel time from buses in the Twin Cities to floating vehicles can reveal new opportunities for other agencies around the world.

\section{Data}

The goal of this research is to relate bus travel time to floating cars along a transit corridor in the Twin Cities metropolitan area. This relation helps to introduce more reliable estimates of travel time for planning new and competitive transit service along the specified corridor. In addition, it can work as a base for adjusting new bus schedules when compared to floating vehicles. The Minnesota Valley Transit Authority (MVTA), which is a relatively small suburban transit provider in the Twin Cities region, is currently planning to expand its service and upgrade levels of service along Cedar Avenue. The Cedar Avenue corridor is planned to incorporate a BRT system in addition to the current regular service. MVTA data collection is currently limited to semi-annual manual passenger counts and several TrackStick Global Positioning System (GPS) units.

To determine current travel times along the study corridor, the research team collected travel time data from two MVTA bus routes serving the Cedar Avenue corridor, Routes 442 and 444, shown in Figure 1. Route 442 is a commuter route that runs south along Cedar Avenue and Highway 77. Of all of the existing MVTA bus routes, Route 442 most closely resembles the service that will be provided by the Cedar Avenue BRT. Route 444 is also primarily a commuter route running south along Cedar Avenue and Highway 77. However, after crossing the Minnesota River, Route 444 turns westward and travels along Highway 13 and several residential 
streets. Route 444 was chosen for data collection to construct comparisons between car and bus travel times on freeways, arterials, and local streets.

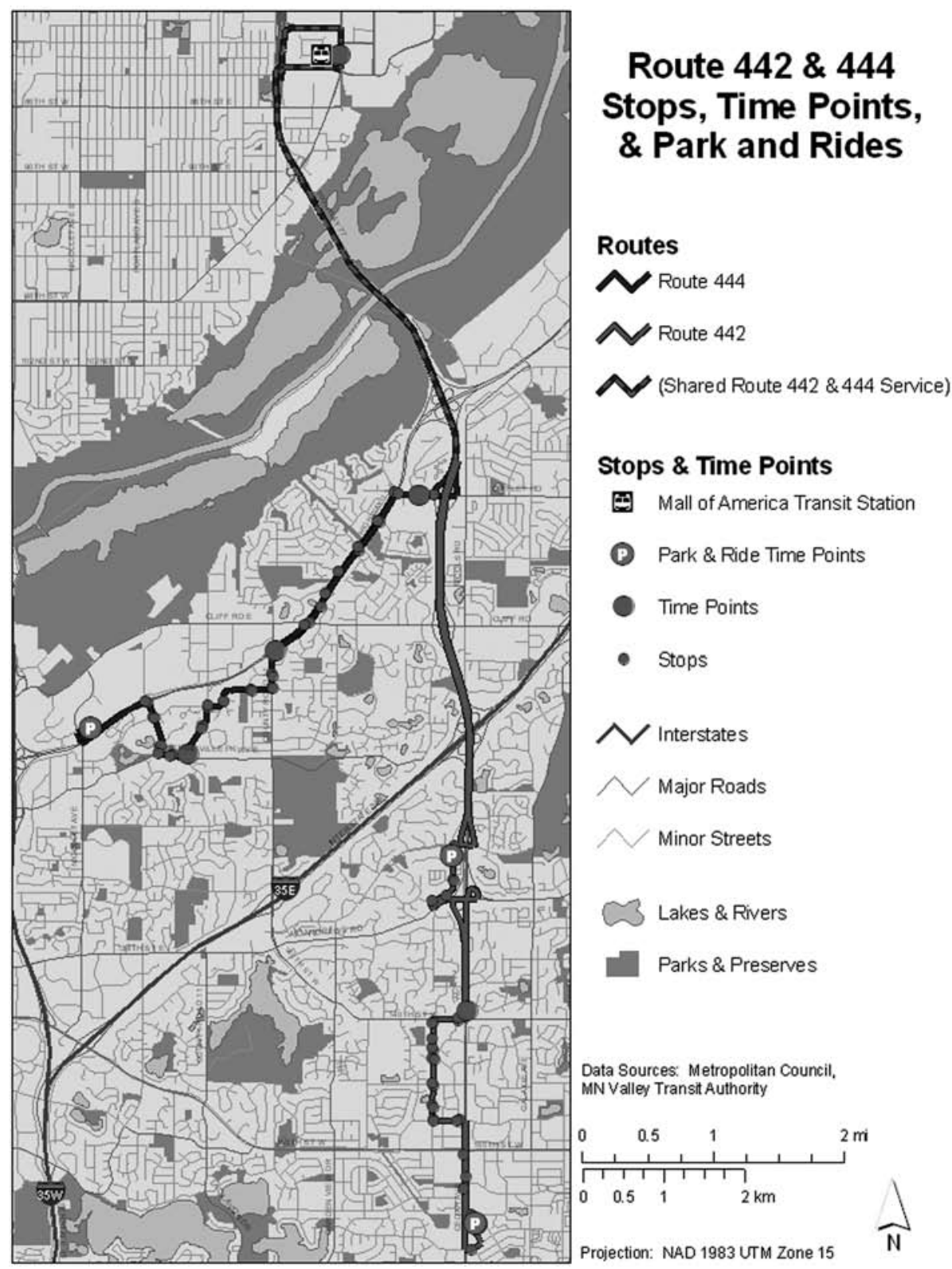

Figure 1. Studied Routes 
Travel time data for buses on these routes were collected using QStarz GPS data loggers provided by the research team and several TrackStick GPS units owned by MVTA. MVTA's existing GPS units were programmed to take a data point at regular time intervals (approximately every 7 seconds), so the research team programmed the QStarz units to record points at the same interval. The research team collected data from buses running on Route 444 during the month of October 2007. Due to contractor issues, data collection on Route 442 was delayed until the following spring. The research team collected data from buses running on this route during the months of March and April 2008. During the fall data collection period, no major weather issues were present that might have an effect on travel time. Data from spring days with inclement weather (i.e., snow storms) were removed from the analysis.

Travel time data for private vehicles on Routes 442 and 444 were collected during the same time periods using probe vehicles equipped with QStarz GPS units. The research team recruited student volunteers to drive their personal vehicles along each studied transit route. Students were instructed to leave the first station on the route at the same time as a bus and to drive at the speed of traffic until they reached the end of the route.

To establish the relationship between travel times for buses and private vehicles in the study area, each bus trip was matched with a probe vehicle trip that departed at approximately the same time. After cleaning and matching the car and bus data, this data collection effort resulted in a sample of 286 matched trips (143 probe vehicle trips matched to 143 bus trips). This sample represents 130 matched trips on Route 442 and 156 matched trips on Route 444. These trips were distributed throughout the day during $A M, P M$, and off-peak periods.

Using these data, it is possible to determine travel times along transit routes. Unfortunately, it is not possible to accurately determine when buses make stops to serve passengers. Many of the stops along Routes 442 and 444 are located on the nearside of signalized or high-traffic intersections. Due to this combination of stop placement and the small amount of passenger activity at most stops (one passenger boarding or alighting at non-park-and-ride stops), it is not possible to distinguish actual passenger stops from regular traffic stops. 


\section{Methodology}

To determine current travel times along the studied corridor and examine the relationship between travel times for personal vehicles and buses, the research team used two levels of analysis. This paper first presents a comparison of travel times for different vehicle types along Routes 442 and 444 as a whole. It then presents a comparison of travel times for different vehicle types along smaller route segments. Routes 442 and 444 provide service to a variety of areas and travel along different types of roads. To evaluate the impact of these different route characteristics on bus and private vehicle travel time, the research team divided the two routes into smaller segments with similar attributes (i.e., speed, travel direction, road classification, etc.) for analysis. Figure 2 illustrates these segments.

Using travel time data for the routes and the analysis segments, the research team conducted basic statistical analyses to determine travel time patterns. Paired $\mathrm{t}$-tests also were used to examine the relationship between car and bus run times. Using only the data for the analysis segments, the research team estimated two different multivariate regression models to determine the influence of various route characteristics on travel time for both buses and private vehicles. The specifications of the models are:

(1) Run Time $=f$ (northbound, $A M, P M$, length, freeway, vehicle, signals, stop signs, bus stops, ramp meters)

(2) Natural Log of Difference between Car and Bus Run Time $=f$ (north bound, AM, PM, length, freeway, county road, signals, bus stops, meters, route)

Table 2 describes each of the dependent and independent variables used in the models. The first model examines the factors contributing to travel time for probe vehicles and buses along analysis segments. The covariants in the regressions represent the most theoretically relevant variables included in empirical studies of this type. A dummy variable for whether each vehicle is a bus or probe is included in this model. Several variables such as number of traffic signals and bus stops are also included to control for operating environment. Run time is expected to be less for private vehicles relative to buses. Run time is also expected to be less for vehicles traveling on freeway segments relative to vehicles traveling on arterials or residential streets. It is expected to increase with the number of possible stops in a segment, number of traffic signals, number of stop signs, and length of the seg- 
Journal of Public Transportation, Vol. 12, No. 3, 2009

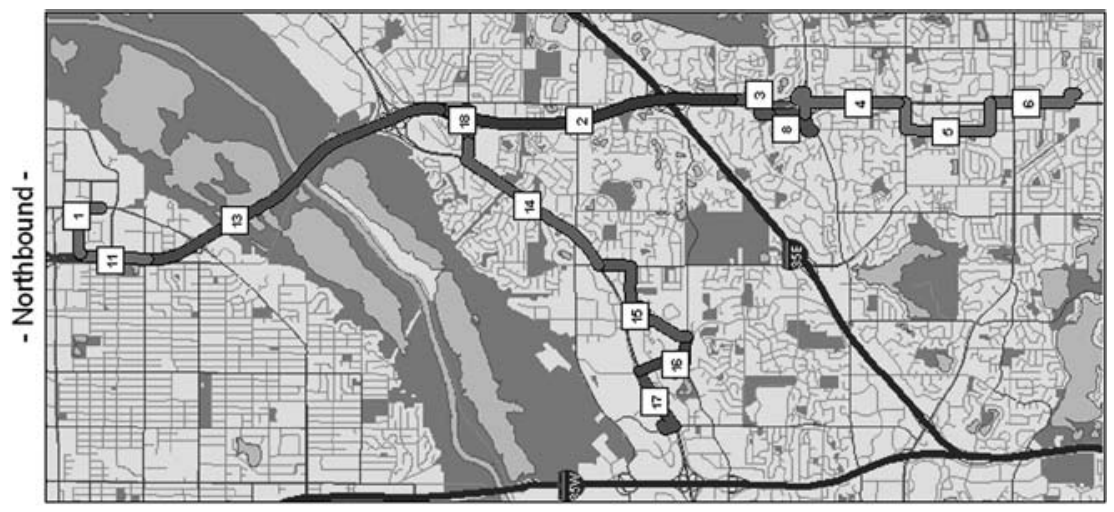

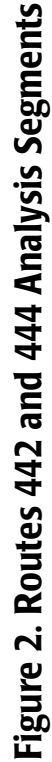
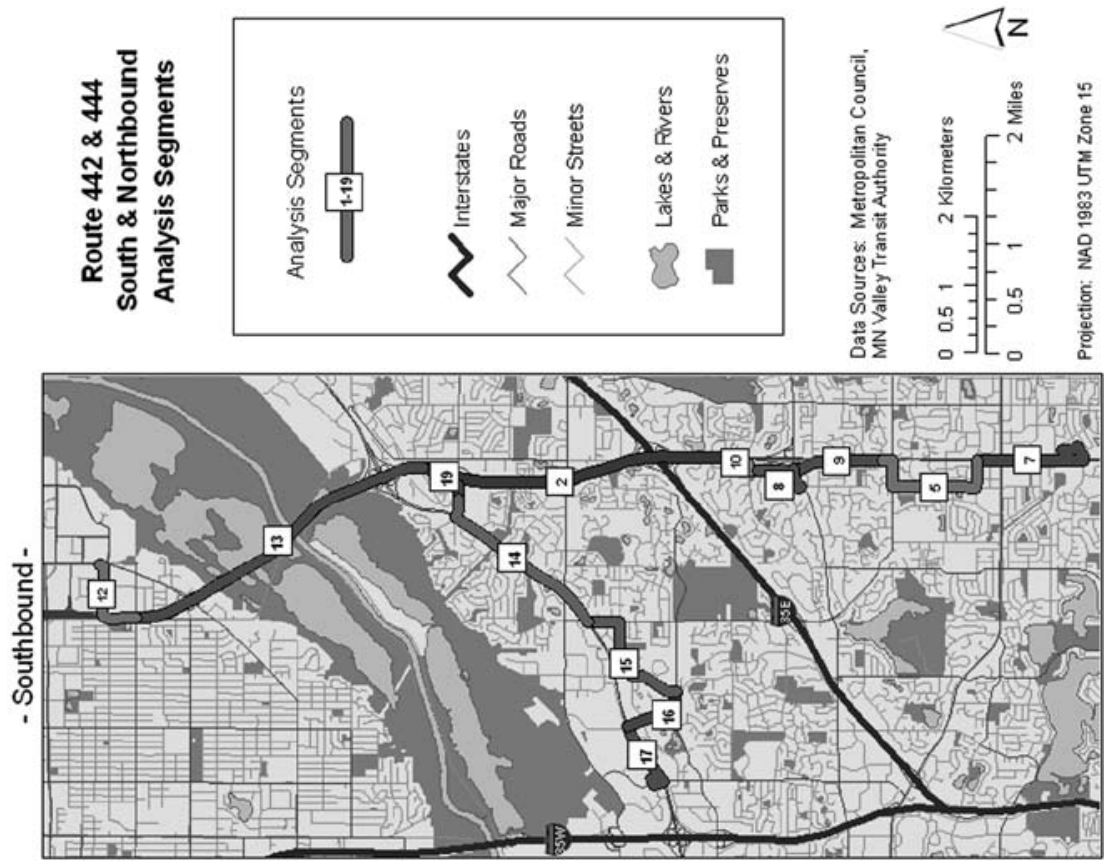
ment. Vehicles traveling during AM or PM peak hours are expected to have longer run times than vehicles traveling during off-peak hours.

The second model evaluates the impact of different route characteristics on the difference between run time for buses and private vehicles. The difference in run time equals the run time for a private vehicle along a segment minus the run time for a bus traveling along the same segment at the same time of day. The dependent variable for this model is the natural log of the difference in run times. This functional form not only helps linearize a nonlinear relationship but also provides a useful interpretation for the coefficients of the independent variables. As a result,

\section{Table 2. Variable Descriptions}

\begin{tabular}{|c|c|}
\hline Variable & Description \\
\hline Run time & The run time along an analysis segment (see Figure 2 ). \\
\hline LN Difference Run Time & $\begin{array}{l}\text { The natural log of the difference between run times for a private } \\
\text { vehicle and bus traveling on the same analysis segment during the } \\
\text { same time of day. }\end{array}$ \\
\hline $\begin{array}{l}\text { Northbound } \\
\text { (traveling towards } \\
\text { downtown) }\end{array}$ & $\begin{array}{l}\text { A dummy variable that equals } 1 \text { if the car or bus is traveling north- } \\
\text { bound (towards downtown Minneapolis). }\end{array}$ \\
\hline AM Peak & $\begin{array}{l}\text { A dummy variable that equals } 1 \text { if the observed car or bus trip started } \\
\text { during the AM peak. }\end{array}$ \\
\hline PM Peak & $\begin{array}{l}\text { A dummy variable that equals } 1 \text { if the observed car or bus trip started } \\
\text { during the PM peak. }\end{array}$ \\
\hline Length of Segment & The length of the analysis segment in kilometers. \\
\hline Freeway & $\begin{array}{l}\text { A dummy variable that equals } 1 \text { if the car or bus is traveling on a } \\
\text { freeway segment (no stops and a speed limit of } 60 \mathrm{mph} \text { ). }\end{array}$ \\
\hline County Road & $\begin{array}{l}\text { A dummy variable that equals } 1 \text { if the car or bus is traveling on an } \\
\text { arterial or county road segment (signalized stops and a speed limit of } \\
40 \mathrm{mph} \text { ). }\end{array}$ \\
\hline Vehicle & A dummy variable that equals 1 if the observed vehicle is a car. \\
\hline \# of Traffic Signals & The number of traffic signals located on the analysis segment. \\
\hline \# of Stop Signs & The number of stop signs located on the analysis segment. \\
\hline \# of Bus Stops & $\begin{array}{l}\text { The number of bus stops located on the analysis segment. This vari } \\
\text { able includes all possible bus stops, not the number of stops actually } \\
\text { made. }\end{array}$ \\
\hline \# of Ramp Meters & $\begin{array}{l}\text { The number of active ramp meters located on the analysis segment. } \\
\text { This variable is equal to } 0 \text { for all off-peak observations. }\end{array}$ \\
\hline Route & $\begin{array}{l}\text { A dummy variable that equals } 1 \text { if the observed trip is along the Route } \\
442 .\end{array}$ \\
\hline
\end{tabular}


the coefficients in this model can be interpreted as the percent change in the difference in run times that results from a one-unit increase in the independent variable. For this model, the research team hypothesized that the same relationships exist with the independent variables, with the exception that the $A M$ and PM peak variables may have negative coefficients because buses may use shoulder lanes in some areas to bypass congested traffic. If the numbers of bus stops and traffic signals have significant positive coefficients in both of these models, it is an indication that providing BRT service with consolidated stops and ITS improvements such as signal priority will lead to significant run time savings.

\section{Travel Time Analysis}

\section{Route Travel Time Analysis}

Using travel time data for the routes, the research team conducted basic statistical analyses to determine run time patterns. Figures 3 through 6 show the run time distributions for buses and private vehicles on Routes 442 and 444. For the 130 matched trips on Route 442, the run times for buses ranged from 21 to 42 minutes. The run times for private vehicles on this route ranged from 17 to 26 minutes, with a median value of 21 minutes. The standard deviation of personal vehicle run times is, not surprisingly, smaller than the standard deviation for buses. This clearly indicates that bus run time is subject to higher variation. The median observed run time for buses is 3.6 minutes longer than that for personal vehicles.

For the 156 matched trips on Route 444, the run times for buses ranged from 17 to 27 minutes, with a median value of 20.3 minutes. The run times for private vehicles on this route ranged from 13 to 24 minutes. The standard deviation of personal vehicle run times on this route is slightly larger than the standard deviation for buses. This indicates a lower variation in running time along the bus route, which can be related mainly to the length of the route. However, it is again the case that the median observed run time for personal vehicles is equal to the minimum observed run time for buses. The difference between median observed run times for buses and personal vehicles on this route is almost the same as that found for Route 442. This fact suggests that the route type, residential or arterial, does not affect the relationship between bus and private vehicle travel times. The median run time for buses on this route is 3.5 minutes longer than that for personal vehicles. Since this finding needs to be validated statistically, a detailed statistical analysis is presented in the following section. 


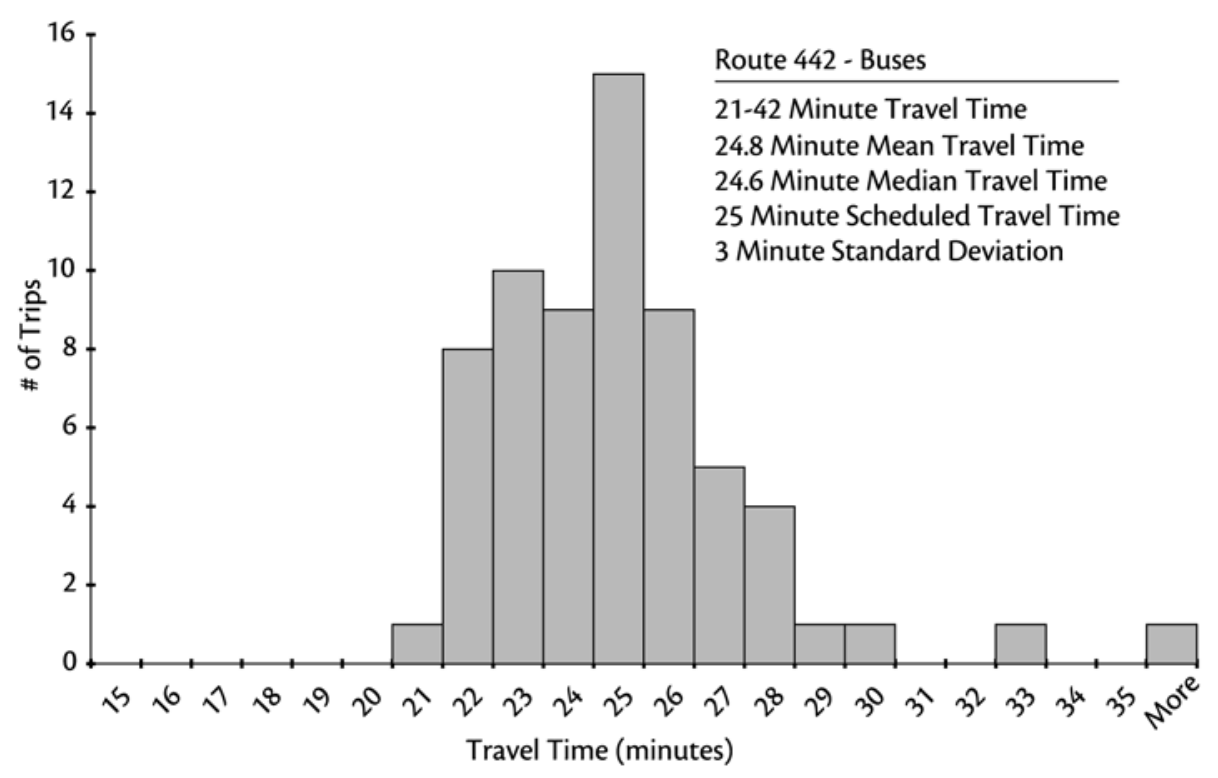

Figure 3. Route 442 Bus Run Time Distribution

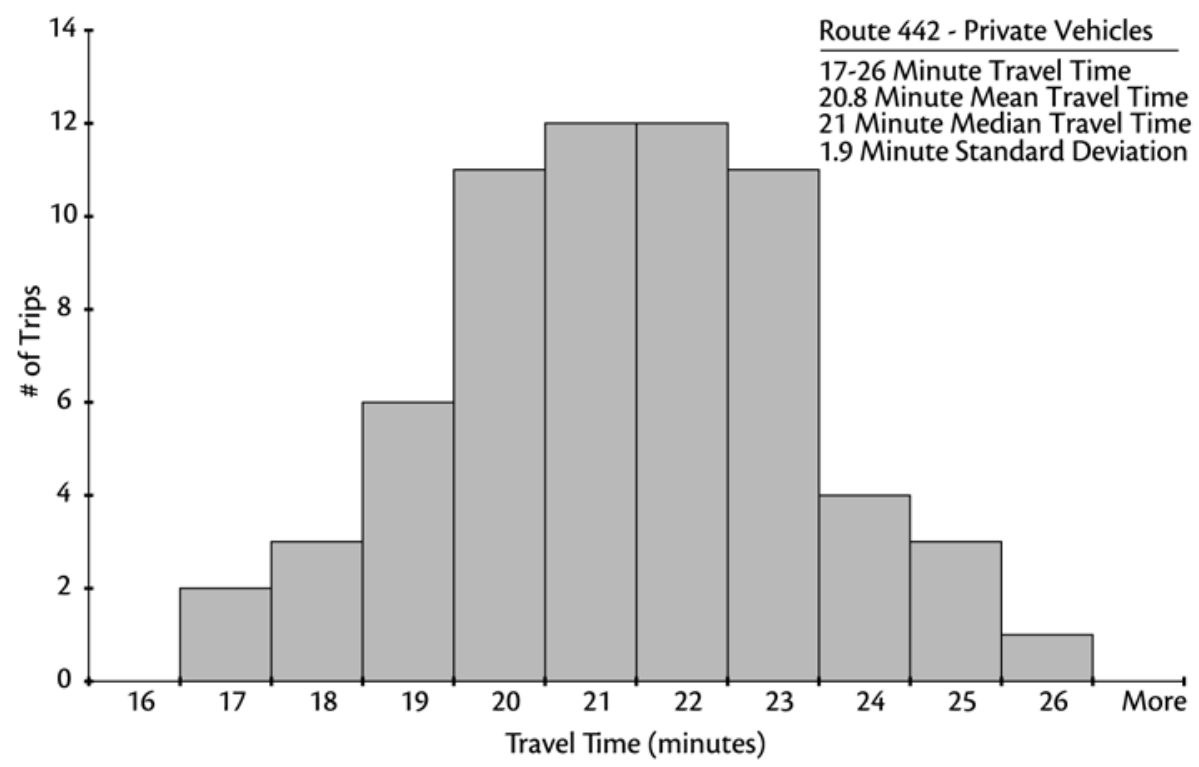

Figure 4. Route 442 Private Vehicle Run Time Distribution 


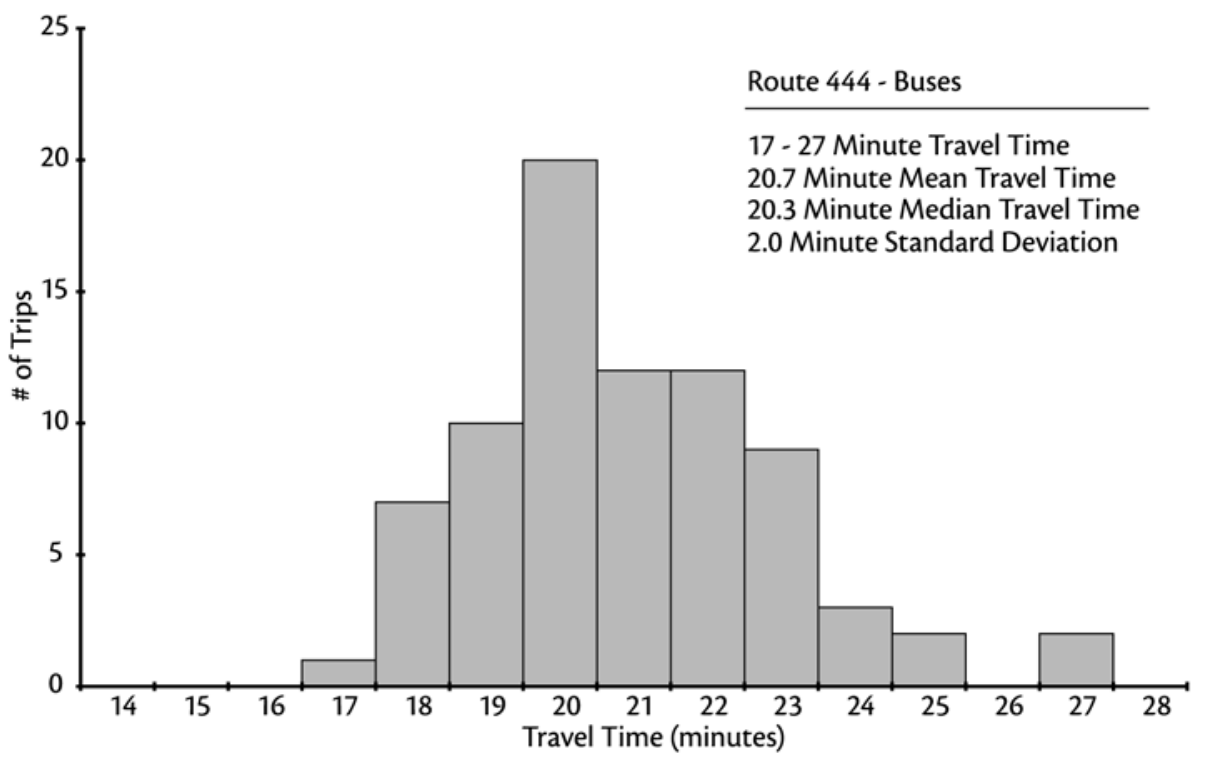

Figure 5. Route 444 Bus Run Time Distribution

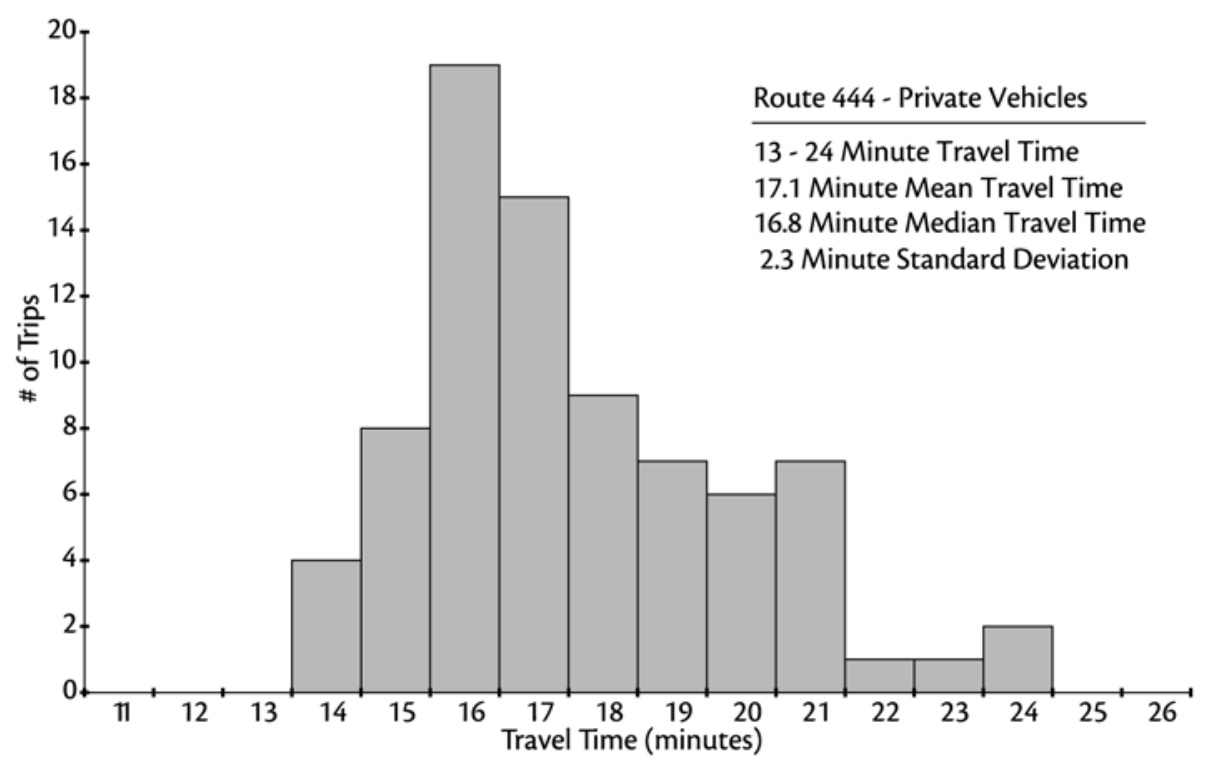

Figure 6. Route 444 Private Vehicle Run Time Distribution 


\section{Statistical Analysis}

\section{Paired T-Tests}

After examining the distributions of run times, the research team used paired $t$-tests to examine the relationship between car and bus run times along routes and route segments. Table 3 presents the results of each of the $t$-test comparisons. Both of the route-level comparisons are significant at the $99 \%$ level of confidence. At the route level, the mean difference between run times for buses and private vehicles is 3.98 minutes for Route 442 and 3.59 minutes for Route 444 . The difference in bus and car run times at the route level ranges from 3.08 to 4.87 minutes for Route 442 and from 2.91 to 4.26 minutes for Route 444 . This statistical analysis indicates that for the bus service to be competitive along either one of the studied routes, it needs a certain amount of travel time savings ranging from 2.91 to 4.87 minutes.

\section{Table 3. Paired T-Test Comparisons}

\begin{tabular}{lllllll}
\hline & \multicolumn{1}{c}{$\begin{array}{c}\text { Mean } \\
\text { Road } \\
\text { Type }\end{array}$} & $\begin{array}{c}\text { 95\% Confidence interval } \\
\text { Difference } \\
\text { (minutes) }\end{array}$ & $\begin{array}{c}\text { of the difference } \\
\text { Lower }\end{array}$ & Upper & $t$ & Sig. \\
\hline Route 442 & Route & -3.98 & -4.87 & -3.08 & -8.87 & .000 \\
Route 444 & Route & -3.59 & -4.26 & -2.91 & -10.56 & .000 \\
All Segments & - & -0.52 & -0.59 & -0.45 & -13.95 & .000 \\
Segment 1 & Local Street & -0.74 & -1.13 & -0.35 & -3.81 & .000 \\
Segment 2 & Freeway & -0.91 & -1.45 & -0.36 & -3.32 & .002 \\
Segment 3 & Local Street & -0.40 & -0.82 & 0.02 & -1.95 & .059 \\
Segment 4 & Arterial & -0.48 & -0.60 & -0.36 & -8.33 & .000 \\
Segment 5 & Local Street & -0.46 & -0.75 & -0.16 & -3.06 & .003 \\
Segment 6 & Arterial & -0.38 & -0.93 & 0.17 & -1.40 & .171 \\
Segment 7 & Arterial & -0.60 & -0.92 & -0.28 & -3.85 & .001 \\
Segment 8 & Local Street & -0.89 & -1.13 & -0.65 & -7.43 & .000 \\
Segment 9 & Arterial & -0.22 & -0.37 & -0.07 & -2.93 & .007 \\
Segment 10 & Local Street & -0.59 & -0.88 & -0.31 & -4.30 & .000 \\
Segment 11 & Arterial & -0.08 & -0.14 & -0.03 & -3.11 & .003 \\
Segment 12 & Local Street & -0.35 & -0.68 & -0.02 & -2.10 & .040 \\
Segment 13 & Freeway & -0.05 & -0.22 & 0.13 & -0.55 & .586 \\
Segment 14 & Arterial & -1.53 & -1.83 & -1.12 & -10.19 & .000 \\
Segment 15 & Local Street & -0.85 & -1.05 & -0.66 & -8.57 & .000 \\
Segment 16 & Local Street & -0.35 & -0.56 & -0.13 & -3.19 & .002 \\
Segment 17 & Arterial & -0.11 & -0.32 & 0.10 & -1.029 & .307 \\
Segment 18 & Local Street & 0.23 & -0.03 & 0.48 & 1.79 & .080 \\
Segment 19 & Local Street & -0.83 & -1.18 & -0.48 & -4.83 & .000 \\
\hline & & & & & &
\end{tabular}


All but three of the t-tests conducted at the route segment level are significant at the $90 \%$ level of confidence. Segments 6 and 13 are mainly the first two segments in each route, while segment 13 is part of a 2.5 -mile segment along highway 77. Observing the statistical output can help in identifying the sections where improvements in run time are needed and can lead to substantial saving and in making the transit service competitive. The second step is to understand the built environment along the selected corridors and the effects of each variable on run time to help in maximizing the savings in run time.

\section{Regression Models}

Using only the data for the analysis segments, the research team estimated two multivariate regression models to determine the influence of various route characteristics on travel time for both buses and private vehicles. The first model examines the factors contributing to travel time for probe vehicles and buses along analysis segments. In this model, observed run time (in seconds) along a route segment is used as the dependent variable. Table 4 shows the output for this model. Note that statistically significant variables are in bold.

Table 4. Run Time Model

\begin{tabular}{lcrr}
\hline Independent Variables & B & \multicolumn{2}{c}{ t } \\
\hline (Constant) & 20.06 & 4.77 & $* * *$ \\
Traveling towards Downtown & -10.75 & -4.22 & $* * *$ \\
AM Peak & 11.26 & 3.51 & $* * *$ \\
PM Peak & 17.02 & 5.22 & $* * *$ \\
Length of Segment & 37.51 & 26.24 & $* * *$ \\
Traveling on Freeway & -11.04 & -1.15 & \\
Vehicle is a Car & -30.27 & -12.28 & $* * *$ \\
\# of Traffic Signals & 25.85 & 25.25 & $* * *$ \\
\# of Stop Signs & 15.80 & 7.42 & $* * *$ \\
\# of Possible Bus Stops & 8.70 & 13.05 & $* * *$ \\
\# of Ramp Meters & -6.42 & -1.66 & $*$ \\
Adjusted R-square & 0.69 & & \\
N & 2,138 & & \\
Dependent Variable & Segment Run time (seconds) \\
\hline
\end{tabular}

* Significant at the $90 \%$ level

*** Significant at the $99 \%$ level 
This model has an R-square of 0.69 , with all variables having a statistically-significant effect on run time except for the freeway variable. In addition, all variables in the model have the expected sign and follow transit operation theory. For example, run time increases by 37.51 seconds for each kilometer a vehicle must travel. Relative to run times during off-peak hours, run time along each segment increased by 11.26 seconds during the AM peak and 17.02 seconds during the PM peak, holding all else constant.

For each traffic signal on a route segment, run time increases by 25.85 seconds. There are currently eight traffic signals located on the Cedar Avenue corridor through which the planned service will pass. If transit signal priority (TSP) is provided at these lights for buses, this would lead to a 3.4-minute run time savings. Each stop sign on a route segment increases run time by 15.8 seconds. By running straight down the Cedar Avenue corridor and avoiding residential areas with stop signs currently served by Route 442, the bus service will gain additional travel time savings. Route 442 currently travels through four stop signs, which add just over one minute to the route's run time. Similarly, each possible bus stop along a route segment increases run time by 8.7 seconds, whether the bus actually stops to serve passengers or not. ${ }^{1}$ By consolidating bus stops and cutting the number of possible stops along Cedar Avenue in half, the bus will achieve more run time reductions. The 20 possible stops along Route 442 currently account for 2.7 minutes of each bus's run time. The Cedar Avenue limited or BRT, alternatively, will serve a longer segment of the corridor with only 10 possible stops, adding only 1.35 minutes to each bus's travel time.

Variables in this model with a negative effect on run time are direction of travel, number of ramp meters, traveling on the freeway, and traveling in a car. All else held constant, northbound trips have a 10.75 second shorter run time on each route segment. Each ramp meter reduces run time by 6.42 seconds. As expected, type of vehicle has the largest negative impact on travel time. On each route segment, private vehicles have a 30.27-second shorter travel time than buses. Route 442 is divided into eight segments southbound and nine segments northbound, which translates into a 4-minute shorter travel time for cars traveling south and 4.5-minute shorter travel time for cars traveling north relative to buses, all else being equal. This difference can be easily minimized if the City and the transit agency implemented some of the above-mentioned strategies for travel time savings. 
The second model evaluates the impact of different route characteristics on the difference between run time for buses and private vehicles. The dependent variable for this model is the natural log of the difference in run times. As a result, the coefficients in this model can be interpreted as the percent change in the difference in run times that results from a one-unit increase in the independent variable. Table 5 shows the outputs of this model.

\section{Table 5. Run Time Difference Model}

\begin{tabular}{llrrr}
\hline Independent Variables & B & \multicolumn{2}{c}{ t } \\
\hline (Constant) & -0.99 & -9.20 & $* * *$ \\
Traveling towards Downtown & -0.21 & -3.01 & $* * *$ \\
AM Peak & 0.18 & 1.98 & $* *$ \\
PM Peak & -0.08 & -0.86 & \\
Length of Segment & 0.16 & 3.78 & $* * *$ \\
Traveling on Freeway & -1.07 & -3.46 & $* * *$ \\
Traveling on County Road & -0.08 & -0.84 & \\
\# of Traffic Signals & 0.19 & 7.04 & $* * *$ \\
\# of Possible Bus Stops & 0.03 & 1.93 & $* *$ \\
\# of Ramp Meters & 0.04 & 0.28 & \\
Route 442 & -0.08 & -1.03 & \\
Adjusted R-square & 0.18 & & \\
N & 762 & & \\
Dependent Variable & Natural Log of Difference & \\
& between Car and Bus Run time \\
\hline * Significant at the 90\% level & & & \\
** Significant at the 95\% level & & & \\
*** Significant at the 99\% level & & & \\
& & & & \\
& & & & \\
& & & & \\
& & & & \\
\end{tabular}

This model has an R-square of 0.18 , with the majority of variables having a statistically-significant impact on the log of the difference between bus and car run times. Again, the variables in this model have the expected signs and follow transit operation theory. The difference between car and bus run times is 18 percent greater during the AM peak hours relative to off-peak hours, all else held constant. For each additional kilometer traveled, the difference between car and bus run times increases by 16 percent. Each traffic signal increases the run time difference by 19 percent due to buses' slower acceleration time and other factors. For each possible stop, the difference in run time increases by 3 percent, whether the bus stops or 
not. The small magnitude of this variable could be because of the large number of possible stops and small number of actual stops being made on the studied routes. Alternatively, some of the impact of stops may be attributed to traffic signals in this model due to the prevalence of stops located on the nearside of signalized intersections along the Cedar corridor. Regardless, these results show that consolidating bus stops and implementing TSP as part of the Cedar Avenue corridor will help to reduce the travel time disparity between buses and private vehicles in the region and increase the attractiveness of transit service.

Several factors have a statistically-significant negative impact on the difference between run times for private vehicles and buses. The difference between car and bus run times is 21 percent less for northbound trips heading towards downtown Minneapolis. On freeway route segments, buses actually had a shorter travel time than personal vehicles on average, all else being equal. This is likely due to the fact that buses can bypass congested traffic and ramp queues on freeway segments of the Cedar Avenue corridor by using bus-only shoulder lanes.

\section{Conclusions/Recommendations}

The analysis presented in this paper highlights several issues related to the Cedar Avenue transit corridor in particular and to transit planning in general. This research has evaluated conditions along the Cedar Avenue corridor that will influence bus and private vehicle travel time. It has also outlined an innovative approach for estimating travel time for new transit lines based on GPS data collected by probe vehicles. The statistical analyses used in this research were conducted at two levels: the route level and the route segment level. The research team's analysis of route level travel time patterns shows that Cedar Avenue corridor buses have greater variation in their run times than vehicles. However, for both of the studied routes, the median travel time for private vehicles was equal to the minimum travel time for buses. The difference between median car and bus travel times for both routes was approximately 3.5 minutes.

The analysis of route-segment-level data provides a more detailed understanding of the relationship between vehicle type, route characteristics, and run time. While personal vehicles have an inherent travel time advantage over buses under existing conditions on the Cedar Avenue corridor (and most major arterials), our analysis shows that altering route characteristics can reduce overall travel time and minimize the travel time disparity between buses and cars. In particular, the 
models presented in this paper lend support to bus stop consolidation and implementation of transit signal priority along the Cedar Avenue corridor. Providing transit signal priority at the eight traffic signals currently located on the corridor would reduce bus travel time by 4 minutes for southbound trips and 4.5 minutes for northbound trips. This strategy would also eliminate the travel time advantage of private vehicles over buses on the corridor, according to our second model. Reducing the number of possible bus stops from 20 to 7 will remove an additional 1.7 minutes from the current bus travel time along this section of the corridor. Bus-only shoulder policies seem to have a great effect on the competiveness of transit vehicles over regular cars; accordingly, it is recommended to use this policy in other regions and when running bus service along congested freeway corridors. Finally, by running straight down the Cedar Avenue corridor and avoiding smaller local streets, the bus will save an additional one minute in travel time that is currently spent at stop signs. In addition to these travel time savings, remaining on the main corridor where there are freeway-like conditions will help to reduce the difference between travel time for buses and personal vehicles even more. Under these conditions, travel time via BRT running along this corridor would be approximately 2.5 minutes shorter than median run time via personal vehicle. This travel time would increase the amenity value of the BRT, attract ridership, and help to ensure the competitiveness of this transit line.

In conclusion, it should be noted that the analyses presented in this paper are based on a very limited run time dataset collected using handheld GPS units. This project was adapted to focus on the Cedar Avenue corridor, and a new methodology was developed to predict travel time for a transit provider with no existing ITS data collection systems. Due to the placement of many MVTA bus stops on the nearside of signalized intersections, the research team was not able to determine when actual passenger stops were being made. Also, budgetary restrictions prevented MVTA or the research team from being able to collect passenger counts for the entire study period. It is recommended that MVTA implement an AVL and APC system.

Future research should include budget for passenger counts for the entire study period. The number of possible stops and actual stops should be included in the future to better model the effects of bus stop consolidations. Other data that should be included in these models and may be available from transit agencies with more advanced ITS systems include smart card use, lift use, bus-only shoulder use, etc. 


\section{Acknowledgments}

This research was funded through Hennepin County, Minnesota; accordingly, acknowledgment is given to Robb Luckow and Larry Blackstad of Hennepin County Community Works \& Transit. The authors would like to express their appreciation to Michael Abegg from MVTA for his support in collecting the data, to the students who volunteered to drive the probe vehicles, and to the Minnesota Traffic Observatory, which supported this research and provided the facilities for conducting the analysis. Finally, the authors would like to thank the three anonymous reviewers for their feedback on the earlier version of the manuscript.

\section{Endnotes}

${ }^{1}$ Unfortunately, using the data collected by handheld GPS units taking points at regular time (as opposed to distance) intervals, it was not possible for the research team to determine when buses actually stopped to serve passengers. In future research, the number of actual stops made as well as the number of possible stops should be included as variables in this model.

\section{References}

Abkowitz, M., and I. Engelstein. 1983. Factors affecting running time on transit routes. Transportation Research Part A 17(2): 107-113.

Abkowitz, M., and I. Engelstein. 1984. Methods for maintaining transit service regularity. Transportation Research Record 961: 1-8.

Abkowitz, M., and J. Tozzi. 1987. Research contributing to managing transit service reliability. Journal of Advanced Transportation 21 (Spring): 47-65.

Bertini, R., and S. Tantiyanugulchai. 2004. Transit buses as traffic probes: Use of geolocation data for empirical evaluation. Transportation Research Record 1870: 35-45.

Furth, P., and T. Muller. 2006. Service reliability and hidden waiting time: Insights from automatic vehicle location data. Transportation Research Record 1955: 79-87. 
Furth, P., and T. Muller. 2007. Service reliability and optimal running time schedules. Paper presented at the Transportation Research Board 86th Annual Meeting.

Guenthner, R. P., and K. C. Sinha. 1983. Modeling bus delays due to passengers boardings and alightings. Transportation Research Record 915: 7-13.

Koenig, J. G. 1980. Indicators of urban accessibility: Theory and application. Transportation 9: 145-172.

Krizek, K. J., and A. M. El-Geneidy. 2007. Segmenting preferences and habits of transit users and non-users. Journal of Public Transportation 10(3): 71-94.

Levinson, H. 1983. Analyzing transit travel time performance. Transportation Research Record 915: 1-6.

Murray, A., and X. Wu. 2003. Accessibility tradeoffs in public transit planning. Journal of Geographical Systems 5(1): 93-107.

Strathman, J. G., K. J. Dueker, T. J. Kimpel, R. L. Gerhart, K. Turner, P. Taylor, et al. 2000. Service reliability impacts of computer-aided dispatching and automatic location technology: A Tri-Met case study. Transportation Quarterly 54(3): 85-102.

Turnquist, M. 1978. A model for investigating the effect of service frequency and reliability on bus passenger waiting times. Transportation Research Record 1978: 70-73.

Welding, P. I. 1957. The instability of a close-interval service. Operational Research Quarterly 8(3): 133-142.

\section{About the Authors}

Ahmed El-Geneidy (ahmed.elgeneidy@mcgill.ca) is an Assistant Professor at McGill University in Quebec, Canada. His research interests include land use and transportation planning, transit operations and planning, travel behavior analysis including both motorized (auto and transit) and non-motorized (bicycle and pedestrian) modes of transportation, travel behavior of disadvantaged populations (seniors and people with disabilities), and measurements of accessibility and mobility in urban contexts. 
JoHn HouRdos (hourdos@umn.edu) is the director of the Minnesota Traffic Observatory at the Department of Civil Engineering, University of Minnesota. His research focuses on microscopic simulation, traffic model calibration, and incident detection and prevention. Recently, in collaboration with the ITS Institute, he designed, assembled, and deployed an array of advanced traffic detection and surveillance stations in the highest freeway accident area in the Twin Cities.

JESSICA HORNING (jhorning@camsys.com) is a transportation planner at Cambridge Systematics in Bethesda, Maryland. She has a master's degree in Urban Planning from the University of Minnesota. Her research interests include land use and transportation planning, transit planning and operations, and active transportation especially cycling. 